\title{
Platelet larceny: spurious hypoxaemia due to extreme thrombocytosis
}

\author{
A. Mehta*, A.E. Lichtin\#, A. Vigg* and J.G. Parambil*
}

ABSTRACT: Rapid oxygen consumption by markedly increased numbers of hypermetabolic leukocytes in leukaemic patients resulting in the apparent diagnosis of hypoxaemia on arterial blood gas analyses is termed leukocyte larceny.

In the present report, a case of polycythaemia vera, extreme thrombocytosis, normal leukocyte counts and arterial hypoxaemia in the absence of clinical, radiological or physiological evidence of lung disease is described.

This pseudohypoxaemia case was established by pulse oximetry, as well as by incubation of a blood specimen with potassium cyanide, and became less significant after the use of cytoreductive agents showed a proportionate increase in arterial oxygen tension as platelet counts decreased on serial arterial blood gas analyses.

The present case report demonstrates spurious hypoxaemia due to extreme thrombocytosis and shows that, beside significant leukocytosis, even markedly elevated platelet counts can cause larceny of arterial blood oxygen.

\section{KEYWORDS: Extreme thrombocytosis, polycythaemia vera, spurious hypoxaemia}

. n 1979, Hess et al. [1] showed that arterial oxygen tension $\left(\mathrm{Pa}_{\mathrm{a}} \mathrm{O}_{2}\right)$ fell at a faster rate in patients with leukocytosis than in control subjects, and that this fall was great enough to result in an incorrect diagnosis of hypoxaemia. This artefactual phenomenon has been described primarily in association with oxygen consumption by the increased numbers of hypermetabolic leukocytes in various types of leukaemia [2-5] and has been termed leukocyte larceny [6]. Recognising this pseudohypoxaemia avoids errors in the interpretation of results and prescription of inappropriate diagnostic and therapeutic interventions [7]. True oxygenation status can be ascertained with pulse oximetry, correction of hypoxaemia by the addition of potassium cyanide $(\mathrm{KCN})$ to the blood specimen or continuous blood gas analysis [4-6].

In the present report, a case of polycythaemia vera (PV), extreme thrombocytosis, normal leukocyte counts and arterial hypoxaemia in the absence of clinical, radiological or physiological evidence of lung disease is described. The pseudohypoxaemia was confirmed by the addition of KCN to the blood specimen, and became less significant after successful reduction of platelet counts following myelosuppressive chemotherapy. This case suggests that pseudohypoxaemia due to the in vitro consumption of oxygen by significantly elevated numbers of platelets should be included in the differential diagnosis of patients with extreme thrombocytosis being evaluated for arterial hypoxaemia.

\section{CASE REPORT}

A 72-yr-old female, who never smoked tobacco, was evaluated at the Cleveland Clinic (Cleveland, $\mathrm{OH}$, USA) for unexplained hypoxaemia on arterial blood gas (ABG) analysis. Her history had begun 3 months previously, when she underwent complete blood count analysis for symptoms of fatigue, revealing a leukocyte density of $8.3 \times 10^{3}$ leukocytes $\mu \mathrm{L}^{-1}$ (normal 4 $11 \times 10^{3}$ leukocytes $\left.\cdot \mu \mathrm{L}^{-1}\right)$, a haematocrit of $56 \%$ (normal 37-47\%), a haemoglobin concentration of $18.7 \mathrm{~g} \cdot \mathrm{dL}^{-1}$ (normal $12-16 \mathrm{~g} \cdot \mathrm{dL}^{-1}$ ) and platelet density of $2,168 \times 10^{3}$ platelets $\mu \mathrm{L}^{-1}$ (normal 150 $350 \times 10^{3}$ platelets $\cdot \mu \mathrm{L}^{-1}$ ). Radioactive chromium51-labelled red blood cells (RBCs) revealed an increased $\mathrm{RBC}$ mass of $38 \mathrm{~mL} \cdot \mathrm{kg}^{-1}$ (normal $<32 \mathrm{~mL} \cdot \mathrm{kg}^{-1}$ ) and reduced serum erythropoietin levels of $4 \mathrm{mU} \cdot \mathrm{mL}^{-1}$ (normal $5-25 \mathrm{mU} \cdot \mathrm{mL}^{-1}$ ). ABG analyses performed in room air (table 1) identified severe arterial hypoxaemia, with a

\section{AFFILIATIONS}

Depts of *Pulmonary, Allergy and Critical Care Medicine, and

"Hematology and Oncology, Cleveland Clinic, Cleveland, $\mathrm{OH}$, USA.

CORRESPONDENCE

J.G. Parambil

Dept of Pulmonary

Allergy and Critical Care Medicine A-90

Cleveland Clinic

9500 Euclid Avenue

Cleveland

OH 44195

USA

Fax: 12164458160

E-mail: parambj@ccf.org

Received:

April 032007

Accepted after revision:

June 282007

STATEMENT OF INTEREST

None declared. 


\begin{tabular}{|c|c|c|c|c|c|}
\hline \multirow[t]{2}{*}{ TABLE 1} & \multicolumn{5}{|c|}{$\begin{array}{l}\text { Comparison of platelet counts and oxygen measurements at various times before and after phlebotomy and } \\
\text { cytoreductive chemotherapy }\end{array}$} \\
\hline & & Platelet counts $\times 10^{3}$ cells $\cdot \mu \mathrm{L}^{-1}$ & $\mathrm{~Pa}, \mathrm{O}_{2} \mathrm{mmHg}$ & $\mathrm{Sa}, \mathrm{O}_{2} \%$ & $\mathrm{Sp}, \mathrm{O}_{2} \%$ \\
\hline \multicolumn{2}{|c|}{3 months before initial visit } & 2168 & 47 & 74 & ND \\
\hline \multicolumn{2}{|c|}{ On initial visit } & 2425 & 40 & 73 & 98 \\
\hline \multicolumn{2}{|c|}{ After incubation with $\mathrm{KCN}$} & 2425 & 94 & 98 & 98 \\
\hline \multicolumn{2}{|c|}{20 weeks after treatment } & 721 & 84 & 97 & 98 \\
\hline
\end{tabular}

$\mathrm{Pa}_{1} \mathrm{O}_{2}$ : arterial oxygen tension; $\mathrm{Sa} \mathrm{O}_{2}$ : arterial oxygen saturation; $\mathrm{Sp}, \mathrm{O}_{2}: \mathrm{Sa}_{1} \mathrm{O}_{2}$ measured by pulse oximetry; $\mathrm{ND}$ : not determined; $\mathrm{KCN}$ : potassium cyanide. $1 \mathrm{mmHg}=0.133 \mathrm{kPa}$.

$\mathrm{Pa}, \mathrm{O}_{2}$ of $6.2 \mathrm{kPa} \quad(47 \mathrm{mmHg}$; normal $\quad 10.6-13.3 \mathrm{kPa} \quad(80-$ $100 \mathrm{mmHg})$ ).

Peripheral blood smears demonstrated increased numbers of erythrocytes with normal morphology along with several normoblasts. Leukocyte numbers were normal without suggestions of cytological atypia. There was thrombocytosis, and giant and hypogranular platelet forms were occasionally observed. Bone marrow biopsy showed hypercellularity with trilineage hyperplasia demonstrating hyperplastic normoblastic erythropoiesis, maturing granulopoiesis without dysplasia and increased megakaryopoiesis with several hyperlobulated megakaryocytes. There was also evidence of intravascular haematopoiesis and absent bone marrow iron stores, and there were no findings of fibrosis. These features were suggestive of the polycythaemic phase of PV.

Despite the bone marrow findings and low serum erythropoietin levels, further testing was conducted in order to identify the aetiology of hypoxaemia, since concerns regarding secondary erythrocytosis existed. Chest radiography and contrast-enhanced computed tomography of the chest, abdomen and pelvis did not identify any abnormalities. Pulmonary function tests revealed normal findings and a 3\% shunt fraction (normal $<5 \%$ ) was obtained from ABG measurements using the $100 \%$ oxygen method. Transthoracic bubble-contrast echocardiography identified normal left and right ventricular function without suggestions of pulmonary hypertension or intracardiac shunting. In order to rule out a high-affinity haemoglobinopathy, measurement of the $\mathrm{Pa}, \mathrm{O}_{2}$ corresponding to an arterial oxygen saturation $\left(\mathrm{Sa}_{2} \mathrm{O}_{2}\right)$ of $50 \%$ gave a value of $3.47 \mathrm{kPa} \quad(26.1 \mathrm{mmHg}$; normal $3.15-3.95 \mathrm{kPa} \quad$ (23.7$29.7 \mathrm{mmHg})$ ). The patient was sent to the Cleveland Clinic for further evaluation.

The initial evaluation revealed an elderly female with normal vital signs and an $\mathrm{Sa}_{1} \mathrm{O}_{2}$ measured by pulse oximetry $\left(\mathrm{Sp}_{\mathrm{p}} \mathrm{O}_{2}\right)$ of $98 \%$. On physical examination, there was splenomegaly that extended $3 \mathrm{~cm}$ below the costal margin, no cyanosis, and normal heart and lung tones on auscultation. The ABG analyses were repeated with simultaneous pulse oximetry (table 1) and the results corroborated previous findings. ABG analyses were repeated after incubating the sample with $\mathrm{KCN}(1 \mathrm{mM}$ final concentration) due to the discrepancy between $\mathrm{Sp}_{\mathrm{p}} \mathrm{O}_{2}$ and $\mathrm{Sa}_{\mathrm{a}} \mathrm{O}_{2}$, and normal $\mathrm{Pa}, \mathrm{O}_{2}$ and $\mathrm{Sa}_{1} \mathrm{O}_{2}$ were demonstrated (table 1), thereby establishing the initial values as pseudohypoxaemia. Pulse oximetry was prescribed in order to further monitor the patient's oxygenation status.

Treatment for PV was instituted utilising phlebotomy and myelosuppressive therapy with hydroxyurea. On returning 6 weeks after treatment initiation, the patient noted resolution of fatigue and the haematocrit and platelet counts were reduced to $46 \%$ and $985 \times 10^{3}$ platelets $\mu \mathrm{L}^{-1}$, respectively. Pulse oximetry continued to give an $\mathrm{Sp}, \mathrm{O}_{2}$ of $98 \%$, and repeat ABG analyses showed an increase in $\mathrm{Pa}_{\mathrm{a}} \mathrm{O}_{2}$ and $\mathrm{Sa}_{1} \mathrm{O}_{2}$ (table 1). At her 20-week visit, the haematocrit and platelet counts were $41 \%$ and $721 \times 10^{3}$ platelets $\mu \mathrm{L}^{-1}$, respectively, and ABG analyses showed further increases in $\mathrm{Pa}_{\mathrm{a}} \mathrm{O}_{2}$ and $\mathrm{Sa}_{\mathrm{a}} \mathrm{O}_{2}$ towards normal values (table 1; fig. 1).

\section{DISCUSSION}

In the original description of Hess et al. [1], the mean leukocyte and platelet counts that demonstrated the rapid fall in $\mathrm{Pa}, \mathrm{O}_{2}$ of arterial blood stored in a syringe at room temperature were $117 \times 10^{3}$ cells $\cdot \mu \mathrm{L}^{-1}$ and $331 \times 10^{3}$ cells $\cdot \mu \mathrm{L}^{-1}$, respectively. It was noted that the type and maturity of the proliferating leukocytes

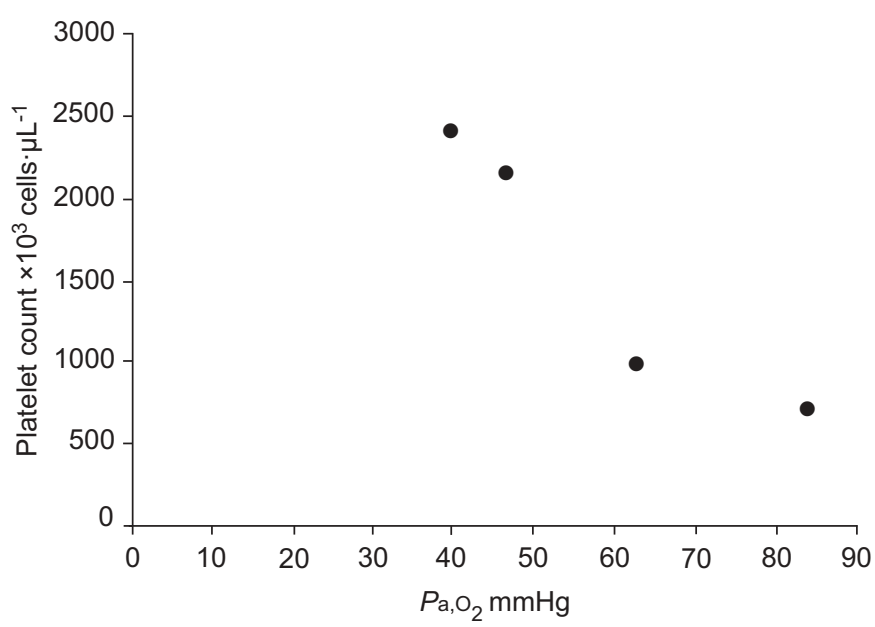

FIGURE 1. Relationship of arterial oxygen tension $\left(\mathrm{Pa}_{\mathrm{a}} \mathrm{O}_{2}\right)$ to platelet count Platelets were anticoagulated with EDTA. $1 \mathrm{mmHg}=0.133 \mathrm{kPa}$. 
appeared to be important in this rate of fall in $\mathrm{Pa}_{\mathrm{a}} \mathrm{O}_{2}$. Since then, several case reports [2-6] have described this phenomenon of leukocyte larceny in various types of leukaemia, based on the postulation that primitive leukaemic cells exhibit higher metabolic rates and cause larger drops in $\mathrm{Pa}_{1} \mathrm{O}_{2}$ than do normal leukocytes [1, 6].

Reticulocytes, platelets and leukocytes are among the constituents of blood that affect $\mathrm{Pa}, \mathrm{O}_{2}$ in shed blood, since oxygen consumption by mature erythrocytes and plasma is negligible, with leukocytes and platelets accounting for most of this phenomenon [1, 6, 8, 9]. In 1911, ONAKA [10] was the first to demonstrate that respiration occurred in plasma after the erythrocytes and leukocytes had been spun down, and correctly attributed this oxygen consumption to blood platelets. Since then, the concept of platelet function has dramatically evolved from that of artefacts and organisms in blood to their being complex integral cells that utilise both aerobic and anaerobic metabolic pathways to generate sufficient amounts of adenosine triphosphate (ATP) for optimal participation in various phases of haemostasis [11, 12]. This intimate coupling of energy metabolism with stimulation and execution of platelet responses, as well as the significantly elevated turnover of cytoplasmic ATP compared with that of most other cells, results in the elevated oxygen consumption of these tiny cells [12-14].

In 1951, DEWARDENER and Young [15] first studied the oxygen consumption of blood in PV and noted increased oxygen utilisation, which affected the estimation of $\mathrm{Sa}_{1} \mathrm{O}_{2}$. They demonstrated that this increased in vitro oxygen consumption was directly proportional to the number of circulating leukocytes, with a mean $\pm \mathrm{SD}$ utilisation of $14.4 \pm 4.9 \mathrm{~mL}$ $\mathrm{O}_{2} \cdot 100 \mathrm{~mL}^{-1}$ blood $\cdot 24 \mathrm{~h}^{-1}$ (normal $5.4 \pm 0.5 \mathrm{~mL} \mathrm{O} \cdot 100 \mathrm{~mL}^{-1}$ blood $\cdot 24 \mathrm{~h}^{-1}$ ). In this study [15], the mean leukocyte and platelet counts were $17 \times 10^{3}$ leukocytes $\cdot \mu \mathrm{L}^{-1}$ and $622 \times$ $10^{3}$ platelets $\cdot \mu \mathrm{L}^{-1}$. Interestingly, one patient had a platelet count of $2,000 \times 10^{3}$ platelets $\mu \mathrm{L}^{-1}$ and consumed $18.8 \mathrm{~mL}$ $\mathrm{O}_{2} \cdot 100 \mathrm{~mL}^{-1}$ blood $\cdot 24 \mathrm{~h}^{-1}$. This value remained elevated at $10.8 \mathrm{~mL} \mathrm{O} \cdot 100 \mathrm{~mL}^{-1}$ blood $\cdot 24 \mathrm{~h}^{-1}$ despite washing out the leukocytes and erythrocytes, suggesting considerable oxygen consumption by the markedly elevated platelet counts [15]. In 1968, Kitchens and NewCOMB [12] studied normal platelet respiration and found that oxygen consumption was directly proportional to the number of platelets in the density range 40$400 \times 10^{3}$ platelets $\mu \mathrm{L}^{-1}$. They also evaluated the rate of oxygen consumption by platelets from normal donors and from patients with various haematological disorders and obtained similar values [12].

With the advent of pulse oximetry, the problem of pseudohypoxaemia can be circumvented [16]. Pulse oximetry measures the in vivo percentage of functional haemoglobin combined with oxygen based on the principle that oxyhaemoglobin and deoxyhaemoglobin absorb light over a range of wavelengths between their peak absorption spectra of $660 \mathrm{~nm}$ and $940 \mathrm{~nm}$, respectively. In the present patient, a pronounced discrepancy between the $\mathrm{Sa}_{1} \mathrm{O}_{2}$ derived from ABG analyses and the $\mathrm{Sp}_{\mathrm{p}} \mathrm{O}_{2}$ was observed when platelet counts were as high as $2,425 \times 10^{3}$ platelets $\mu \mathrm{L}^{-1}$. Following successful reduction of platelet counts to $721 \times 10^{3}$ platelets $\mu \mathrm{L}^{-1}$ with phlebotomy and hydroxyurea chemotherapy, there was better correlation between the $\mathrm{Sp}_{\mathrm{p}} \mathrm{O}_{2}$ and $\mathrm{Sa}_{1} \mathrm{O}_{2}$ (table 1). Metabolic inhibitors of cellular respiration, such as $\mathrm{KCN}$, have been shown to immediately inhibit oxygen consumption by platelets to $14 \%$ of normal at concentrations of $1 \mathrm{mM}$ $[12,17]$. This was demonstrated in the present patient by the normalisation of $\mathrm{Pa}_{1} \mathrm{O}_{2}$ and $\mathrm{Sa}_{1} \mathrm{O}_{2}$ after the addition of $\mathrm{KCN}$, and helped to establish the diagnosis of pseudohypoxaemia.

Pulmonary complications causing hypoxaemia are uncommon in PV and, when they occur, are usually caused by either infections or thromboembolic events $[18,19]$. Other rare complications include pulmonary or pleural extramedullary haematopoiesis and pulmonary arterial hypertension [19, 20]. These complications can easily be excluded by corroborating clinical findings with chest imaging and echocardiographic results. Although secondary erythrocytosis is more common than PV, decreased serum erythropoietin levels accompanied by characteristic bone marrow biopsy features are highly suggestive of PV, even in the presence of arterial hypoxaemia. Nowadays, the diagnosis can be greatly enhanced by performing cytogenetic studies for the JAK2 ${ }^{\mathrm{V} 617 \mathrm{~F}}$ mutation, although this was not undertaken in the present case [21]. In the present patient, realisation of this would have limited subsequent tests towards potential pulmonary complications of PV and not towards an exhaustive battery of studies for the evaluation of the various causes of secondary erythrocytosis.

In conclusion, although secondary erythrocytosis due to hypoxaemia is more common than polycythaemia vera and patients with polycythaemia vera may show hypoxaemia secondary to pulmonary complications, caution is suggested with regards to relying on arterial blood gas determination alone for the assessment of true oxygenation status in patients with polycythaemia vera and extreme thrombocytosis, especially with platelet counts of $>2,000 \times 10^{3}$ platelets $\mu \mathrm{L}^{-1}$, since spurious hypoxaemia due to oxygen consumption can create difficulty in the interpretation of results. The increased rate of oxygen consumption in these patients is most probably due to elevated numbers of platelets rather than a hypermetabolic clone of malignant cells [12]. In this context, pulse oximetry can be a useful tool for establishing and further monitoring true oxygenation status. Metabolic inhibitors of platelet respiration, such as potassium cyanide, can also be helpful in establishing the diagnosis of pseudohypoxaemia.

\section{REFERENCES}

1 Hess CE, Nichols AB, Hunt WB, Suratt PM. Pseudohypoxemia secondary to leukemia and thrombocytosis. N Engl J Med 1979; 301: 361-363.

2 Loke J, Duffy TP. Normal arterial oxygen saturation with the ear oximeter in patients with leukemia and leukocytosis. Cancer 1984; 53: 1767-1769.

3 Gorski TF, Ajemian M, Hussain E, et al. Correlation of pseudohypoxemia and leukocytosis in chronic lymphocytic leukemia. South Med J 1999; 92: 817-819.

4 Sacchetti A, Grynn J, Pope A, Vasso S. Leukocyte larceny: spurious hypoxemia confirmed with pulse oximetry. J Emerg Med 1990; 8: 567-569.

5 Mizock BA, Franklin C, Lindesmith P, Shah PC. Confirmation of spurious hypoxemia using continuous 
blood gas analysis in a patient with chronic myelogenous leukemia. Leuk Res 1995; 19: 1001-1004.

6 Fox MJ, Brody JS, Weintraub LR. Leukocyte larceny: a cause of spurious hypoxemia. Am J Med 1979; 67: 742-746.

7 Charoenratanakul S, Loasuthi K. Pseudohypoxemia in a patient with acute leukemia. Thorax 1997; 52: 394-395.

8 Jalavisto E. Oxygen consumption of blood and plasma and the percentage of reticulocytes. Acta Physiol Scand 1959; 46: 244-251.

9 Bird RM, Clements JA, Becker LM. The metabolism of leukocytes taken from peripheral blood of leukemic patients. Cancer 1951; 4: 1009-1014.

10 Onaka M. Über Oxydationen im Blut. [On oxidation in the blood.] Z Physiol Chem 1911; 71: 193-199.

11 Antognetti R, Fracchia P, Robustelli G. Behavior of oxygen consumption, anaerobic glycolysis, and blood platelets' enzyme activities in patients with essential thrombopenia. Haematologica 1963; 48: 930-936.

12 Kitchens CS, Newcomb TF. Human platelet respiration. J Appl Physiol 1968; 25: 581-585.

13 Holmsen H. Platelet metabolism and activation. Semin Hematol 1985; 22: 219-240.

14 Mürer EH, Hellem AJ, Rozenberg MC. Energy metabolism and platelet function. Scand J Clin Lab Invest 1967; 19: 280-282.
15 DeWardener HE, Young IM. Oxygen consumption of polycythemic blood in vitro with a note on the arterial oxygen saturation in primary polycythemia. Clin Sci 1951; 10: 497-510.

16 McMorrow RC, Mythen MG. Pulse oximetry. Curr Opin Crit Care 2006; 12: 269-271.

17 Akkerman JW, Gorter G, Soons H, Holmsen H. Close correlation between platelet responses and adenylate energy charge during transient substrate depletion. Biochim Biophys Acta 1983; 760: 34-41.

18 Schwarcz TH, Hogan LA, Endean ED, Roitman IT, Kazmers A, Hyde GL. Thromboembolic complications of polycythemia: polycythemia vera versus smokers' polycythemia. J Vasc Surg 1993; 17: 518-523.

19 Dingli D, Utz JP, Krowka MJ, Oberg AL, Tefferi A. Unexplained pulmonary hypertension in chronic myeloproliferative disorders. Chest 2001; 120: 801-808.

20 Tzankov A, Krugmann J, Mikuz G. Glottis edema and interstitial pulmonary disease as a result of extramedullary hemopoiesis in polycythemia vera rubra causing asphyctic death. J Clin Pathol 2003; 56: 79.

21 Tefferi A, Sirhan S, Lasho TL, et al. Concomitant neutrophil $J A K 2^{\mathrm{V} 617 \mathrm{~F}}$ mutation screening and $P R V-1$ expression analysis in myeloproliferative disorders and secondary polycythemia. Br J Haematol 2005; 131: 166-171. 